\title{
Ethnomathematical Practices Among Ifugao: InputTo Learning Package In Plane And Solid Geometry
}

\author{
Roger D. Capua \\ Ifugao State University, Potia Campus, Alfonso Lista Ifugao, Philippines \\ capuaroger@gmail.com
}

Article History: Received: 10 November 2020; Revised 12 January 2021 Accepted: 27 January 2021; Published online: 5 April 2021

\begin{abstract}
This study focused on the development of a culture-based learning package in Ethnomathematical Plane and Solid Geometry based on the ethnomathematical practices of the Ifugaos. Descriptive developmental approach was used to assess the ethnomathematical practices, and the level of validity and readability of the developed learning package. Results revealed that the following ethnomathematical practices are still very much observed by the Ifugaos: festivals and dances, rice farming, musical instruments, ethnic food preparations, basket weaving, and wood carving. The validity of the developed learning package obtained a rating of passed in content, format, presentation, and organization and up-to-datedness of information. The readability statistics showed that the developed learning package is easy to comprehend and suitable to intended readers and learners since it can be understood by at least Grade 7 students. The developed learning package is recommended for use as teaching learning instructional material in Plane and Solid Geometry subject.
\end{abstract}

Keywords: Mathematics education, culture-based instructional material, ethnomathematics, learning package

\section{Introduction}

A quiet revolution has been taking place in the area education for the Indigenous People (IP) of the Philippines. There are initiatives and programs on IP education all over the country in formal and non-formal settings in an effort to provide a culturally rooted and relevant education to the indigenous youth and adults (Alangui, 2017). The Philippine government, through the Department of Education exerted efforts to offer a kind of education that is non-alienating and sensitive to the needs and asperations of the indigenous people. The increase of IP education programs may be seen as a response to years of discrimination, marginalization and neglect of the Philippine government for the indigenous people's education (Abadiano, Turner, \& Valerie, 2011). A national framework opens the way for an IP education that is approachable, to their context, respects their identities and encourages the value of their traditional knowledge, skills and other aspects of their cultural heritage.

Today, Mathematics is confronted with a dilemma and issues that are more challenging and that it encompasses the diversity of the learners. It implies that the socio-cultural background of every individual should be taken into account as part of the learning process Rubio (2016), Sharma and Neupane (2016), and Balamurugan (2015). Moreover, the DepEd Order No. 62 s. 2011 by adopting the National Indigenous People Education Policy Framework also emphasizes the country's commitment to achieve its Education for All (EFA) advocacy. This is important particularly in the policy declaration no. 15 letter $\mathrm{c}$, which is to provide resources and environment to IP learners.

In response to the need for accounting for the socio-cultural background of each learner, schools have been preserving the culture through Ethnomathematics as a research program in the history and philosophy of mathematics with pedagogical implications (Alangui, 2017, \& Abacan-Tuguic, 2016). The contention of this study, is to give ideas on how mathematics as subject can be valued by students and even teachers through understanding its cultural aspects. The connection of the students with the concepts is relevant in order to learn the applications of some mathematical concepts in real life situations (Lipka \& Irhke, 2008).

In any learning situation and for learning of ethnomathematics to take place we have to consider the different concerns based on Bruner's Theory. They are understanding, readiness, independence and motivation (David, 2017). A learning package is specially designed to provide the learners the most explicit information the students need. Learners can continue from one lesson to the other without difficulty of understanding concepts since topics were arranged from the most basic to the most complex one. 
Readiness is another concern in learning. Subject matter and learning experiences must be provided at the level of the learner. The teacher should consider previous the personal experiences with the subject matter of the students. Although readiness may take a longer time, the teacher must bring down the level of simplicity of the lesson to the level of understanding of the learners so that they will be ready to receive instruction (Gagto, 2018).

Learning package sequence of activities, demonstrate specific lessons; hence, the learners are expected to acquire maximum understanding. The developed learning package was made to be a learner-friendly that is why the learning designs and skills activities used were simple that is within students' comprehension level and follows procedural process that makes it understandable and learnable. It starts with the basic concepts leading to a higher level of learning that provided a gradual development of learners' acquisition of skills.

The learning package contain a set of activities, where the students are provided to determine and measure the preparedness of the students' mastery of a particular lesson. They are considered instructional materials or exercises that would give a much better learning that could reinforce mastery learning (Nardo \& Hufana, 2014). The learning package sum up the learning theories and specifically applied the effect of each learning theory in the illustrative example provided in the module (Gagto, 2018). Furthermore, the exercise skills provided directly related learning opportunities for the students' self-assessment.

Given all these, to the best knowledge of the researcher, there has been little discussion on the incorporation of culture or indigenous knowledge systems in mathematics education and in concretizing principles of Etnomathematics in the curriculum through the development of an instructional material to be used in the culturally-rich province of Ifugao with no studies yet dealt with the preparation of ethnomathematical learning package. The ideas of mathematics in cultural practices involves designing tasks that are contextualized in the cultural heritage based on different ways of knowing in order to help us to replicate on certain mathematical concepts as well as on the nature of mathematical knowledge. Several studies on the same aspect were also tried in our country. However, several challenges were observed like the inadequacy of learning materials; change of curriculum to K-12; inadequate preparedness of teachers to teach the Ethnomathematics approach and learning readiness of the students.

Ethnomathematics approach can be a means in achieving and providing students with mathematical content and skills that allow them to successfully command modern mathematics (Rowlands \& Carson, 2002). As Lipka (2002) observed, students who learn Mathematics in an ethnomathematical program do better on standardized mathematics tests. Integrating mathematical methods and principles from the learner's culture into the formal academic curriculum can support them with their own mathematical experience to have a better understanding and can apply mathematical principles (Adam, 2004).

The development of the learning package will contribute to the effective learning competences of the student and effective teaching competency of the Mathematics teachers. It adds to the body of knowledge in ethnomathematics education and can also be used as an important indigenous model in Mathematics education.

\section{Framework of the Study}

This study is anchored in the Mathematics Education Framework; learning theories (cooperative learning theory, constructivism, experiential learning, discovery and inquiry based and reflective learning); the ethnomathematical practices as the indigenous knowledge; and the ADDIE model in the development of the learning package.

The twin goals of the mathematics education are critical thinking and problem solving. Critical thinking is the intellectually disciplined method of actively and skillfully conceptualizing synthesizing, analyzing, applying and evaluating information generated by experience. Mathematical problem solving is finding a way around a difficulty around an obstacle and finding a solution to a problem that is unknown. The theories and concepts used in the study were significant in the development of the learning package focused on culture-based learning in ethnomathematics education.

Cooperative learning theory is a student-centered and instructor-facilitated instructional strategy in which a small group of students is responsible for its own learning and the learning of all group members. Interaction among students of the same group can acquire and practice the elements of a subject matter in solving a problem and complete a task or achieve a goal. Students will work in the group during different activities. As such students will develop a positive relationship and establish an environment where academic accomplishments are valued (Har, 2013).

Theory of constructivism is a theory views learning as an active process that results from self-constructed meaning. Constructivist learning environment entails students to use their prior knowledge and experience to in formulating new, related and adaptive concepts in learning. In order for the students to develop the ability to construct their own knowledge, the role of the teacher becomes more of a facilitator (Kurt, 2011). 
Experiential learning according to Yardley (2012) involves constructing knowledge and meaning from real-life experience. This could serve either as an alternative or as a complement to lectures. The different activities that will be experienced by the students will enable them to have fun while learning.Experiential learning are enhancers of student's cognitive growth by means of observing and developing true to life ethnomathematical practices that brings learning to action as depicted in all activities in the developed learning package.

Discovery and inquiry-based learning backing the idea that students learn when they make use of personal experiences to discover concepts, facts and relationships. Justice, Rice and Warry (2009) believes that discovery and inquiry-based learning increase students' motivation, active approach to learning, academic skills and intellectual habits.

Reflective learning theory highlights that learning originates from our experiences and can be continuously updated through the process of recording and thinking about one's. A very important aspect of reflective learning is that it is a process in which one can learn about one's self (Mathew, Mathew, \& Peechattu, 2017).

Ethnomathematics refers ethno as the code of behavior which came from their ethnomathematical practices; myth, on their belief when planting and harvesting rice, etc.; symbols in their design of native attire, hunting, fishing, and other equipment's used by the Ifugaos in their everyday living. Mathema refers to their performing activities such as measuring, classifying and modeling for instance in measuring the length and width in the construction of house and carving and basketry models. Ethnomathematics then relates the member of distinct cultural groups that have a cultural tradition, codes, symbols, myths and specific ways of reasoning (Amit \& Quoder, 2016).

The ADDIE model which is the most-known instructional model was used as a basis in developing the learning module of Ethnomathematics. This model refers to Analysis, Design, Development, Implementation, and Evaluation (Macaraeg, 2014) which provided a step by step process that enabled instructional designers plan and create training programs with this framework in order to make sure that their instructional products are effective and procedures are efficient. The analysisinvolves the initial practices that determines the learning problem, sets goals and objectives and analyzes the audiences' schema and other essential attributes of the target audience. Design is the method of clarifying the learning goals, deciding an appropriate assessment tool, determining and analyzing an effective learning content and selecting learning materials that support the content is the scope of this stage. Development is an alignment to the second stage, that comprises the formation of the learning content and the production of the learning materials. Implementation is the plan put into practice. The training procedures for both learner and teacher were laid out. Additionally, learning materials were disseminated to the target learners and material evaluation was done subsequently. Evaluation is integrated into each stage of the ADDIE framework. The summative evaluation identified what has been learned and reported to the target learners and teachers the progress in alignment to the learning objectives.

Mathematical Curriculum in Philippine IP Education Programwas based on the Philippine 1987 Constitution under Article XIV mandates to education: "encourage non-formal, informal, and indigenous learning systems as well as independent, self-learning, and out of school youth study programs, mostly those that answer to community needs." One of the most important policy declarations on IP Education Policy Framework was on providing adequate and culturally-appropriate learning resources and environment to IP learners. Rosa and Orey (2016) stressed that educators should understand the cultural roots of other culture in order to value the ideas, procedures and ethnomathematical practices used by the students. There are many approaches that can be used in teaching ethnomathematics that use the cultural experience as vehicles to making mathematics learning more meaningful, and to provide the students with understanding of mathematical knowledge as rooted in their sociocultural environments (Yee \& Bostic, 2014, Rosa, 2015, Alangui, 2017).

The researcher gained better insight and comprehension of the aforementioned theories, concepts, ethnomathematical practices and ADDIE model that, have great essence in the teaching and the learning of mathematics which have a significant bearing in the conceptualization of this study and the development of the output material.

\section{Objectives}

The study aimed to develop a culture-based learning package in Ethnomathematical Plane and Solid Geometry crafted from the observed ethnomathematical practices of the Ifugaos.

Specifically, this study determined the 1) extent of observance of the ethnomathematical practices among the Ifugaos; 2) the learning package in Plane and Solid Geometry that can be developed using the observed ethnomathematical practices; 3) the level of validity of the developed learning package; and 4) the level of readability of the developed learning package. 


\section{Research Design}

This study utilized the descriptive developmental research method. It is descriptive in nature since it described the ethnomathematical practices and the validity of the learning package. There were twelve (12) experts in the field of Mathematics and Culture who served as evaluators of the developed learning package in Ethnomathematical Plane and Solid Geometry.

In developing the learning package in Ethnomathematical Plane and Solid Geometry, the researcher went through the following stages: planning, development and content validation.

In the planning stage, the researcher made a survey on the extent of observation of the ethnomathematical practices from experts in the field of culture and made a document analysis on CMO 75 s. 2017, the syllabus in Plane and Solid Geometry and the IP Education Program competencies.

In crafting the learning package, the researcher followed the ADDIE model (Analysis, Design, Development, Implementation and Evaluation). In order to check the accuracy and appropriateness of the content, the validators/evaluators validated the learning package twice leading to the readability index using the Test Readability Consensus Calculator.

\section{Results and Discussion}

\section{Extent of observance on the Ethnomathematical Practices of the Ifugaos}

The ethnomathematical practices observed and performed by the local residents of Ifugao as indicated in Table 1 showed that the very much observed practices of the Ifugao were on landforms (2.50), rice production (2.43), festivals and dances (2.56), costumes and accessories (2.51), rice wine making (2.77), basket weaving (2.49) and wood carving (2.61) and the moderately observed were on fishing tools (1.98), stone walls (2.19), house constructions (2.23), and musical instruments (2.33). A grand mean of 2.42 which was described to be very much observed was the overall rating on the extent of observance of the ethnomathematical practices of the Ifugaos. These practices were inputs in the development of the learning package.

Table 1. Extent of Observance of Ethnomathematical Practices of the Ifugaos

\begin{tabular}{|c|c|c|c|c|}
\hline \multicolumn{3}{|c|}{ ETHNOMATHEMATICAL PRACTICES } & \multirow{2}{*}{$\begin{array}{l}\text { Mean } \\
2.50\end{array}$} & \multirow{2}{*}{$\begin{array}{l}\text { DR } \\
\text { VMO }\end{array}$} \\
\hline 1. & \multicolumn{2}{|l|}{ Landforms } & & \\
\hline 2. & \multicolumn{2}{|l|}{ Fishing tools } & 1.98 & MO \\
\hline 3. & \multicolumn{2}{|l|}{ Rice Production } & 2.43 & VMO \\
\hline 4. & \multicolumn{2}{|c|}{ Stones Walls (Topeng/tuping) } & 2.19 & MO \\
\hline 5. & \multicolumn{2}{|c|}{$\begin{array}{l}\text { House Construction, Ifugao Architecture and types of Ifugao } \\
\text { Houses }\end{array}$} & 2.23 & MO \\
\hline 6. & \multicolumn{2}{|c|}{ Festivals and Dances } & 2.56 & VMO \\
\hline 7. & \multicolumn{2}{|c|}{ Weaving and wearing costumes/accessories } & 2.51 & VMO \\
\hline 8. & \multicolumn{2}{|c|}{ Playing musical Instruments } & 2.33 & MO \\
\hline 9. & \multicolumn{2}{|c|}{ Bayya (rice wine making) } & 2.77 & VMO \\
\hline 10. & \multicolumn{2}{|c|}{ Indigenous rice recipe making } & 2.47 & VMO \\
\hline 11. & \multicolumn{2}{|c|}{ Munlaga (Basket weaving) } & 2.49 & VMO \\
\hline 12. & \multicolumn{2}{|c|}{ Munpaot/ Munpa-ot (Wood carving) } & 2.61 & VMO \\
\hline \multicolumn{3}{|c|}{ Grand Mean } & 2.42 & VMO \\
\hline \multicolumn{5}{|l|}{$\overline{\text { Legend: }}$} \\
\hline \multicolumn{5}{|c|}{ Weighted Mean $\quad$ Descriptive Equivalent } \\
\hline & $2.34-3.00$ & \multicolumn{3}{|l|}{ Very Much Observed (VMO) } \\
\hline & $1.67-2.33$ & \multicolumn{3}{|l|}{ Moderately Observed (MO) } \\
\hline & $1.00-1.66$ & \multicolumn{3}{|l|}{ Least Observed (LO) } \\
\hline
\end{tabular}


These findings are supported by Ngohayon (2011) and Carating, et al (2014) who mentioned that the mountain peaks of the Cordillera mountain have fertile slope that where root crops and vegetables are produced and the water coming from the forests goes down to creeks and gullies which drain into the rice terraces of Ifugao province.

Ngohayon (2011) and Habito and Ealdama (2019) mentioned that rice production of native rice using indigenous farming tools is part of the Ifugao culture.

The results of the findings are similar with the study of Sarmiento (1999) and Matenge, et al (2015) stating that among the cultural communities, food provides a way for them to relate to others especially in social gatherings, etc. which are usually planned around food. To them sharing or preparing traditional ethnic foods for different occasions has symbolic meaning attached to the food they served (Eusebio, et al 2015).

Labhat et al (2011), Gonzales and Ngohayon (2015) and Remme (2017) recorded that the native dances performed during rituals, festivals and weddings, have rhythmic steps, body and hand movements. Again Labhat et al. (2011) supports the above findings and described that gangha (gongs) are commonly used only in the Ifugao native dances. Zamora (2012), and Reyes (2014) also confirmed the above result by saying that local music using local instruments is a major source of enjoyment and satisfactions to visitors and tourist in a destination.

The Ifugao house architectural design is strongly created from amugawan trees which are used mainly for the posts (buried 50 centimeters below the ground) and locked in with stones (Balangcod, 2010).

Another result is supported by Reyes (2014) and Pazon and Del Rio (2018) when they stressed that locally made baskets and wood carving are more durable that attracts tourist to a destination.

\section{The Learning Package}

The crafting of the learning package for Ethnomathematical Plane and Solid Geometry was based on CMO 75 series of 2017. Ethnomathematical Plane and Solid Geometry is composed of four (4) chapters and aimed at developing reasoning, applying properties and problem-solving skills in the study of Geometric Relation, Triangle Congruent, Quadrilaterals, Similarities, Inequalities, Circles, Coordinate Geometry, and Measurement of Geometric Figures.

Each chapter was divided into several lessons that follow a logical sequence appropriate to the learning needs of the students and considering the prerequisite skills of each mathematical concept. The flow of the lesson follows the ADIDS (Activity, Discussion, Input, Discussion, and Synthesis) method of teaching integrating Ifugao culture specifically the ethnomathematical practices with an overreaching objective of providing an effective and engaging learning experience for the students.

Every chapter was divided into lessons. The number of lessons depends on the coverage of the chapter. Each lesson or group of lessons had the following elements: title, exploration, develop your skills, practice your skill, essential learning, and exercise your skill.

The third part of the developed learning package consists of the appendices for the necessary tables test answers and references. The learning package contains margin features to reinforce understanding on salient points and give interesting facts and trivia related to the lesson.

\section{Level of Validity of the Learning Package}

The learning package in Ethnomathematical Plane and Solid Geometry was subjected to a validity test along the following indicators: content, format, presentation and organization, and accuracy and up-to-datedness of information. The questionnaire was adopted from the Department of Education (DepEd) Guidelines and Processes for Learning Resources Management Development System (LRMDS) Assessment and Evaluation (2009), DO no. 76 (2011) and DM no. 441 (2019) rating Sheet for Print Supplementary Materials.

A group of professional experts in the field of Mathematics and culture from the academe evaluated the level of validity of the learning package from one (1) to three (3) where 3 and above were passing score and below three (3) as the failing score. The learning package must have a total mean score of 21 and above for content and format; 15 and above for presentation and organization; and 18 and above for up-to-datedness of information to be able to pass the validation criteria.

Table 2 shows the level of validity of the learning package in the four areas namely: content, format, presentation and organization and accuracy and up-to-datedness of information. The learning package was evaluated with validity index of 28.00 as to content, 71.50 as to format, 20.00 as to presentation and organization and 23.92 for accuracy and up-to-datedness of information. Overall, the learning package obtained an overall total score of 143.42 describe as a highly valid instructional material. 
The results obtained clearly emphasize that the developed learning package is an appropriate instructional material for first year college, that is now ready to be used by both the students and teachers to enhance new learning in Ethnomathematical Plane and Solid Geometry.

Table 2. Summary Evaluation of the Validity of the Learning Package

\begin{tabular}{lcc}
\hline \hline Feature of the Learning Package & Score & DR \\
\hline Content & 28.00 & Passed \\
Format & 71.50 & Passed \\
Presentation and Organization & 20.00 & Passed \\
Accuracy and Up-to-datedness of Information & 23.92 & Passed \\
Overall & 143.42 & Passed \\
\hline \hline
\end{tabular}

Legend:

StatusContent Format Presentation and Organization Up-to-datedness of Information Overall

$\begin{array}{llll}\text { Passed } 21 \text { and above } & 15 \text { and above } & 18 \text { and above } & 108 \text { and above } \\ \text { Failed below } 21 & \text { below } 15 & \text { below } 18 & \text { below } 108\end{array}$

The finding conforms with Rivera (2011) interpretation that high validity means that topics in the learning package is a salient matter in mathematical competency of the students. It is also well-organized according to the sequence of topics which was designed to cater the needs of the students in learning mathematics.

The findings of high validity also mean that the material is an acceptable reference material for the students in helping them to think logically, systematically and scientifically in order to have a better understanding of the concepts to be learned.

\section{Readability of the Learning Package}

The developed learning package were subjected to readability testing. Readability as defined by Shen (2017), is the attempt to improve texts, to derive rules for communicating more effectively and for accessing success at communication. The two factors affecting readability are the physical factors such as typeface, font size, spacing, layout, and extratextual aids like charts, diagrams, pictures, semantic mapping, etc. and the reader factors such as the readers' prior knowledge about the subject discussion, their motivation, their interest and reading ability.

The Flesch Reading Ease tool, a software readability online utility, was used to determine the level of readability of the developed learning package. The four measures that were used from this tool are: 1) the Flesch Kincaid Reading Ease which measures the reading difficulty of the learning package, 2) the Gunning Fog Score, 3) Smog Index, and 4) the Coleman Liau Index which was used to determine the grade level of the students who can comprehend the text.

Table 3 on next page shows the readability statistics of the learning package. The mean index on Flesch Kincaid Reading Ease is 65.82. It indicates that the learning package has a description rating of Easily Understood by 12 to 15 -year-old students. The text on the learning package are easy to comprehend and understood by the Grade 11 students since it is within their capability level.

Table 3. Readability Score of the Developed of the Learning Package

\begin{tabular}{|c|c|c|c|c|c|c|}
\hline \multirow{2}{*}{$\begin{array}{l}\text { Readability Statistics } \\
\text { (U.S. Grade Level) }\end{array}$} & \multicolumn{4}{|c|}{ Chapter } & \multirow{2}{*}{$\begin{array}{l}\text { Mean } \\
\text { Score }\end{array}$} & \multirow{2}{*}{ Grade Level } \\
\hline & 1 & 2 & 3 & 4 & & \\
\hline $\begin{array}{l}\text { Flesch Kincaid Reading } \\
\text { Ease }\end{array}$ & 61.98 & 64.4 & 70.81 & 66.1 & 65.82 & 8 th to 9 th grade \\
\hline Gunning Fog Score & 10.51 & 10.68 & 10.98 & 10.98 & 10.79 & HS Junior \\
\hline SMOG Index & 10.81 & 10.72 & 10.7 & 10.92 & 10.79 & HS Junior \\
\hline Coleman Liau Index & 8.37 & 7.63 & 4.5 & 6.14 & 6.66 & $7^{\text {th }}$ Grade \\
\hline
\end{tabular}

Legend:

Flesch Kincaid Reading Ease Scoring Key:

Range of Score

School Level
Descriptive Equivalent 

$60-70$
$8^{\text {th }} \& 9^{\text {th }}$ Grade
Easily Understood

Gunning Fog Score, Smog Index, and Coleman Liau Index Index Scoring Key:

$\begin{array}{cl}\text { Score Index } & \text { Reading Level by grade } \\ 11 & \text { High School Junior } \\ 10 & \text { High School Sophomore } \\ 9 & \text { High School Freshman } \\ 8 & \text { Eighth Grade } \\ 7 & \text { Seventh Grade } \\ 6 & \text { Sixth grade }\end{array}$

The mean Gunning Fog Score is 10.79 which shows that the learning package are readable that even a high school junior student can read and understand it. The mean SMOG Index is 10.79 which also shows that it is readable even with high school junior students. The mean Coleman Liau Index is 6.66, indicates that the learning package is also readable for the $7^{\text {th }}$ grader students. The results imply that the developed learning package may be understood on its first reading by seventh to eleventh grade students.

Based on the findings on the readability of the developed learning package, it ensures that the contents of the learning package are easy to comprehend and suitable to the intended readers and learners since it can be understood by at least Grade 7 students. These are basically the learners who graduated in the $\mathrm{K}$ to $12 \mathrm{Basic}$ Education Curriculum who have undergone the 12-year basic education cycle. These findings jive with the study of Bansiong (2019) whose localized and contextualized science textbooks had a standard level of difficulty and appropriate to its intended learners.

\section{Conclusions}

Based on the findings of the study, it can be concluded that the ethnomathematical practices were highly observed by the Ifugaos and were extensively expressed and utilized in the development of the learning package in Ethnomathematical Plane and Solid Geometry; the ethnomathematical practices among the Ifugaos can be integrated into developing learning packages in Plane and Solid Geometry; the high validity level of the developed learning package implies that the learning package in Ethnomathematical Plane and Solid Geometry is deemed appropriate and suitable to the target students; and the developed learning package has a standard level of difficulty in terms of readability, thus, it is easy to understand and are comprehensible to the expected end-users.

\section{Recommendations}

On the basis of the above conclusions, the following recommendations are offered.

1. Classroom teacher may use the ethnomathematical practices in the different phases of mathematics instruction to provide students localized and contextualized learning experiences.

2. Learning materials developers may include ethnomathematical approach in developing learning materials in all level of education.

3. Administrators and teachers may adopt this developed learning package as a textbook or learning material.

4. The developed ethnomathematics learning package may be utilized by other State Colleges and Universities who have students with diverse cultural groups.

5. Seminars, workshops and trainings may be organized for Mathematics teachers in using ethnomathematical approach in teaching for all levels.

6. Further study may be conducted in using ethnomathematics in agri-business subjects and allied courses

\section{Acknowledgement}

This paper has become a reality with the kind support and help of many individuals. The Researcher would like to extend his sincere thanks to all of them. 
Foremost, he wants to offer this endeavor to our GOD Almighty for the wisdom he bestowed upon me, the strength, peace of my mind and good health in order to finish this research.

This work would not have been made possible without the financial support of the Commission on Higher Education (CHED)for the scholarship granted which enabled the researcher to continue his studies and the Ifugao State University family headed by the former and current president, Dr. Serafin L. Ngohayon and Dr. Eva Marie Codamon-Dugyon respectively for allowing him to be a full-time scholar.

In a very special way, the researcher is thankful to his adviser, Dr. Eduard M. Albay who never stopped believing that he will be able to accomplish this piece of work. His unselfish support and encouragement for the realization of this work is indeed incomparable.

The researcher is especially indebted to Dr. Adorinda M. Sarmiento, former dean College of Human Ecology and Dr. Manuel P. Sarmiento, former professor NVSU who have been his research consultants and were supportive of his career goals. They encouraged him to pursue this goal.

To all the professors of DMMMSU-SLUC College of Graduate Studies, who never stopped believing that he will be able to accomplish this piece of work.

\section{References}

Abbacan-Tuguic, L. (2016). Geometry through kalinga indigenous tattoo designs: Using indigenous materials in teaching mathematics of the 21st century learners. International Journal of Advanced Research in Management and Social Sciences, 5(6), 682-689.

Adam, S. (2004). Ethnomathematical ideas in the curriculum. Mathematics Education Research Journal, 16(2), 49-68.

Alangui, W. V. (2017). Ethnomathematics and culturally relevant mathematics education in the philippines. In Ethnomathematics and its Diverse Approaches for Mathematics Education (pp. 183-208). Springer, Cham.

Amit, M., \& Qouder, F. A. (2017). Weaving Culture and Mathematics in the Classroom: The Case of Bedouin Ethnomathematics. In Ethnomathematics and its Diverse Approaches for Mathematics Education (pp. 23-50). Springer, Cham.

Balangcod, T. D. (2010). Indigenous Plant Resources for Houses and Construction Materials Used by the Kalanguya in Tinoc, Ifugao, Philippines. Philippine Scientist, 47.

Balamurugan, M. (2015). Ethnomathematics; An Approach For Learning Mathematics From Multicultural Perspectives. International Journal Of Modern Research And Reviews, 716-720.

Bansiong, A. J. (2019). Readability, content, and mechanical feature analysis of selected commercial science textbooks intended for third grade Filipino learners. Cogent Education, (just-accepted), 1706395. https://www.tandfonline.com/doi/full/ 10.1080/2331186X.2019.1706395

Carating, R. B., Galanta, R. G., \& Bacatio, C. D. (2014). The soils of the lowlands. In The Soils of the Philippines (pp. 51-106). Springer, Dordrecht.

Commission on Higher Education. (2017). CMO 75 s. 2017. Policies, standards, and guidelines for Bachelor of Secondary Education. Quezon City, Philippines: Commission on Higher Education.

David, L. (2017). Discovery Learning (Bruner). Learning Theories. https://www. learning-theories. com/discovery-learning-bruner. html.

DepEd. (2009). Guidelines and Processes for LRMDS Assessment \& Evaluation

Department of Education (2011). DO 62 s. 2011. Adopting the National Indigenous Peoples (Ip) Education Policy Framework. Quezon City, Philippines: Department of Education.

DepEd (2019). DM no. 441 s. 2019. Guidelines and Processes for LRMDS Assessment and Evaluation of Locally Developed and Procured Materials.

Eusebio, M., Ceron, M., Acabado, S. B., \& Krigbaum, J. (2015). Rice pots or not? Exploring ancient Ifugao foodways through organic residue analysis and paleoethnobotany. National Museum Journal of Cultural Heritage, 1, 11-20.

Gagto, R.G. (2018). Development of Modules in Pre-Calculus and Basic Calculus. (Unpublished Doctoral dissertation). Don Mariano Marcos Memorial State University, Agoo, La Union.

Gonzales, N. A. P., \& Ngohayon, S. L. (2015). Indigenizing the Curriculum: Teaching at the Ifugao State University, Philippines. International Journal of Sciences: Basic and Applied Research (IJSBAR) 20(1), 3252

Habito, C. D. L., \& Ealdama, S. J. G. (2019). Identity Construction, Social Media, and Ifugao Rice Terraces Conservation of Indigenous People's Youth Through Appreciative Inquiry. International Journal of Social Ecology and Sustainable Development (IJSESD), 10(4), 47-59. Retrieved on February 2, 2020 from https://www.igi-global.com/article/identity-construction-social-media-and-ifugao-rice-terraces-conservationof-indigenous-peoples-youth-through-appreciative-inquiry/234390 
Har, L. B. (2013). What is cooperative learning? Hongkong Institute of Education. Retrieved on January 15, 2019, from search.ebscohost.com database

Justice, C., Rice, J. \& Warry, W. (2009). Academic skill development-inquiry seminars can make a difference: evidence from a quasi-experimental study. International Journal for the Scholarship of Teaching and Learning 3(1). Retrieved on January 16, 2019, from https://www.learning-theories.org/doku.php?id=instructional_ design:inquiry-based_learning

Kurt, S. (2011). Use of the constructivist approach in architectural education. Elsevier Publishing Company. $\begin{array}{lllll}\text { Retrieved on } & \text { January } & 17, & 2019, & \text { from }\end{array}$ https://www.researchgate.net/profile/Sevinc_Kurt/publication/251713981_Use_of_constructivist_approach_i n_architectural_education/links/56c60d2f08ae8cf828fe9eb3/Use-of-constructivist-approach-in-architecturaleducation.pdf

Labhat, M. B., Malingan M.P., \& Napiloy E.W. (2011). Dances and Festival. Ifugao Indigenous Knowlegde Workbook. Ifugao State University. Nayon, Lamut, Ifugao.

Lipka, A. (2002). Effective Standards-Based Practices for Native American Students: A Review of Research Literature.

Lipka, J., \& Irhke, D. (2008). Yup'ik Cosmology to School Mathematics: The Power of Symmetry and Proportional Measuring. Springer Science+Business Media B.V.

Macaraeg, M. (2014). Development and Validation of Game-Based Lessons in Science and Health. EInternational Scientific Research Journal, 1(1). Retrieved on January 14, 2019, from http://webcache.googleusercontent.com/search?q=cache;U-kF1p4Z01sJ;

Matenge, S. T., Merwe, D. V. D., Hanli, D. B., Magdalena, J. C., \& Annamarie, K. (2015). Consumers' beliefs on indigenous and traditional foods and acceptance of products made with cow pea leaves. Retrieved on January 29, 2020, from http://41.204.161.209/bitstream/handle/11295/107045/matenge-Consumers $\%$ E2\% 80\%99\%20beliefs\%20on\%20indigenous\%20and\%20traditional\%20foods.pdf?sequence=1\&isAllowed=y

Mathew, P., Mathew, P., \& Peechattu, P. J. (2017). Reflective practices: A means to teacher development. Asia Pacific Journal of Contemporary Education and Communication Technology (APJCECT), 3(1), 126131.Retrieved on January 16, 2019, from https://apiar.org.au/wp-content/uploads/2017/02/13_EDU-126131.pdf

Nardo, M. T. B., \& Hufana, E. R. (2014). Development and evaluation of modules in technical writing. American Journal of Educational Research, 2(6), 341-350. Retrieved on February 12, 2020 from https://scholar.google.com/scholar?hl=en\& as_sdt=0\%2C5\&q=development+and+evaluation+of+modules+in+technical+writing $+\& b$ tnG $=$

Ngohayon, S. L. (2011). Ifugao Indigenous Knowledge (IK) Workbook. Ifugao State University

Pazon, A. N. R., \& Del Rio, J. M. P. (2018). Materials, Functions and Weaving Patterns of Philippine Indigenous Baskets. Asian Journal of Multidisciplinary Studies, 1(2).

Remme, J. H. Z. (2017). Ethnographies Returned: The Mobilisation of Ethnographies and the Politicisation of Indigeneity in Ifugao, the Philippines. In Handbook of Indigenous Religion (s) (pp. 294-308). Brill.

Reyes, X. (2014). Harnessing the Cultural Resources of Nueva Vizcaya. Dissertation, University of the Philippines, Diliman, Quezon City.

Rivera, F. D. (2011). Cultural and Blind-Specific Issues and Implications to Visual Thinking in Mathematics. In Toward a Visually-Oriented School Mathematics Curriculum (pp. 241-268). Springer, Dordrecht.

Rowlands, S., \& Carson, R. (2002). Where would formal, academic mathematics stand in a curriculum informed by ethnomathematics? A critical review of ethnomathematics. Educational Studies in Mathematics, 50(1), 79102.

Rosa, M. (2015). A mixed-methods study to understand the perceptions of high school leaders about English language learners (ELLs): The case of mathematics. Jornal Internacional de Estudos em Educação Matemática, 4(2).

Rosa, M., \& Orey, D. C. (2016). State of the art in Ethnomathematics. In Current and future perspectives of ethnomathematics as a program (pp. 11-37). Springer, Cham.

Rubio, J. S. (2016). The Ethnomathematics of the Kabihug Tribe in Jose Panganiban, Camarines Norte, Philippines. Malaysian journal of mathematical sciences, 10, 211-231.

Sarmiento, A. M. (1999). Food consumption patterns and food beliefs of the Gaddangs of Nueva Vizcaya [Philipines].

Sharma, T., \& Neupane, R. (2016). Crafting cultural intelligence in school mathematics curricula: a paradigm shift in Nepali school education. International Journal for Research in Mathematics Education, 6(1), 285 308.

Shen, Y. (2017). On Improving Text Readability by Creating a Personal Writing Style. English Language Teaching, 10(3), 95-100. Retrieved on February 15, 2020 from https://eric.ed.gov/?id=EJ1130022

Yardley, S., (2012). Experiential learning: AMEE guide No. 63. Medical teacher, 34(2), e102-e115. 
Yee, S. P., \& Bostic, J. D. (2014). Developing a contextualization of students' mathematical problem solving. The Journal of Mathematical Behavior, 36, 1-19.

Zamora, C. F. (2012). A study of the musical instruments of Ifugao in the Cordillera Region, Northern Philippines 